\title{
Quality of life and clinical and demographic characteristics of patients with cutaneous squamous cell carcinoma submitted to tumor resection by double-bladed scalpel ${ }^{*}$
}

\author{
Daniel Ongaratto Barazzetti ${ }^{1}$, Pedro Henrique Ongaratto Barazzetti ${ }^{2}$, Bárbara Thomé Cavalheiro ${ }^{3}$, Jorge \\ Bins Ely ${ }^{4}$, Daniel Holthausen Nunes ${ }^{5}$, Ana Maria Nunes de Faria Stamm ${ }^{6}$
}

DOI: http:/ / dx.doi.org/10.1590/abd1806-4841.20197842

\begin{abstract}
BACKGROUND: Non-melanoma skin cancer accounts for a third of all malignancies registered in Brazil, with squamous cell carcinoma (SCC) being one of its subtypes. It develops in photo-exposed areas, affecting social habits and causing negative influence on quality of life (QoL).

Овлестіves: To evaluate QoL in patients with primary cutaneous SCC.

Methods: A cross-sectional study was performed in patients with clinical diagnosis of SCC, corroborated by dermoscopy and confirmed by histopathology; prior to resection of the tumor using the double-blade scalpel technique, a questionnaire on the Dermatology Life Quality Index (DLQI) was applied.

RESULTS: Among the 46 evaluated patients, mean age was $67.1 \pm 16.0$ years, with a predominance of males, low educational level and socioeconomic status, Fitzpatrick II phototype, history of outdoor work, and tumor location in exposed photo areas. Mean DLQI was $4.02 \pm 0.63$, and in the categorization, 11 (23.9\%) had a moderate to severe negative effect on QoL. The skin tumor had a negative impact on daily activities (33\% of cases), treatment effects (30\%), and symptoms and feelings (29\%). STUDY LIMITATIONS: There is no gold standard instrument for assessing QoL in dermatological patients.

CONCLUSION: In the study sample, one-fourth of patients with SCC had a moderate to severe negative effect on quality of life.

Keywords: Skin neoplasia; Carcinoma, Squamous Cell; Quality of life; Surgery, plastic; Dermatology
\end{abstract}

\section{INTRODUCTION}

Skin cancer, currently the most frequent neoplasia in Brazil, is classified in the melanoma and non-melanoma subtypes, the latter accounting for one-third of all malignant tumors recorded in the country. The National Cancer Institute (INCa) has estimated 85,170 new cases in men and 80,410 in women in 2018, based on national epidemiological studies indicating a $29.0 \%$ increase in males and $32.8 \%$ in females in the occurrence of non-melanoma skin tumors. ${ }^{1,2}$ When assessing non-melanoma tumors, $75 \%$ are basal cell carcinoma (BCC), 20\%, squamous cell carcinoma (SCC), and $5 \%$ other subtypes.

SCC develops from pre-neoplastic alterations, including keratosis and actinic cheilitis, and diagnosis is based on clinical char- acteristics and complemented with dermoscopy, but histological confirmation is necessary to establish the prognosis and adequate management of the lesion..$^{3-5}$ The main risk factor for the development of this neoplasia is exposure to ultraviolet (UV) rays, but other factors such as ionizing radiation, chronic inflammation, atrophic diseases (post-burn and post-irradiation scar), immunosuppression, HPV infection (types 16 and 18), chemical agents, smoking, and alcohol use have also been reported. ${ }^{4-6}$ Treatment includes excisional biopsy with histopathological control of margins. ${ }^{7.8}$

The improvement in health-related quality of life (HRQoL), defined as perception of the effects of the disease and the treatment

\footnotetext{
Received 08 Nov 2017.

Accepted 03 Jun 2018 Florianópolis (SC), Brazil.

Financial support: None.

Conflict of interest: None.

Department of Plastic Surgery, Universidade Federal de Santa Catarina (SC), Brazil.

Medical student, Universidade Federal de Pelotas, Pelotas (RS), Brazil.

Department of Anesthesiology, Universidade Federal de Santa Catarina (SC), Brazil.

Department of Operating Technique and Experimental Surgery, Universidade Federal de Santa Catarina (SC), Brazil.

Department of Dermatology, Universidade Federal de Santa Catarina (SC), Brazil.

Department of Clinical Medicine, Universidade Federal de Santa Catarina (SC), Brazil.
}

Work conducted at the Plastic Surgery and Burn Service, Hospital Universitário Polydoro Ernani de São Thiago, Universidade Federal de Santa Catarina, 
in its physical, psychological, and social aspects, is an important treatment target in skin cancer, since the treatment can cause functional and aesthetic limitations. ${ }^{9,10}$ The diagnosis per se and the possibility of developing a second primary skin cancer, even after the cure of initial tumor, can cause anxiety. ${ }^{11}$

Based on this premise, we proposed a study to assess QoL in patients with diagnosis of primary cutaneous SCC prior to resection of the tumor by double-bladed scalpel (DBS), treated at a public teaching hospital in the South of Brazil.

\section{METHODS}

This was an observational, cross-sectional epidemiological study with an analytical component, conducted at the Plastic Surgery and Burn Clinic in a public teaching hospital in a university in the South of Brazil from March to December 2016. We initially assessed 54 patients ages 18 years and older, consecutively, with clinical diagnosis of SCC, screened by clinical dermatologists using dermoscopy as an ancillary tool. Anatomical pathological examination was performed in paraffin at the Pathology Service in this same hospital, which confirmed the neoplasia in 50 cases.

Demographic, clinical-surgical, and lifestyle data were collected before the surgical procedure, as well as application of the quality of life questionnaire. ${ }^{12} \mathrm{At}$ this stage, four more patients were excluded because they were unable to complete the questionnaire, leaving a total sample of 46 patients.
The patients' demographic and clinical-surgical characteristics were assessed, and the anatomical pathological diagnosis and quality of life score were defined for the lesion, the latter measured by the Dermatology Life Quality Index (DLQI), a generic instrument developed for diseases of the skin and connective tissue, with translation and cross-cultural validation in Brazilian Portuguese. ${ }^{12,13}$ The score, shown in chart 1 , consists of ten questions, grouped in six domains (symptoms and feelings, daily activities, leisure, work and school, interpersonal relations, and treatment). On the 'treatment' item, the answers to question 10 considered surgical and non-surgical treatments of the target skin lesions, since patients were initially treated in Basic Health Units (Chart 1). The data were keyed into a computerized teledermatology system, and patients were then treated by this hospital's surgical team in the South of Brazil. Most of the patients were attending periodic consultations and assessments or were using topical treatments for the skin lesions, and were thus considered in treatment. Each question is scored from 0 (nothing/ not relevant) to three (extremely), on a Likert scale. The values for this index vary from 0 to 30 , in which zero (0) indicates absence of effects on life and 30 indicates a very large effect. The final score is classified as: $0-1=$ no effect; $2-5=$ small; $6-10=$ moderate; $11-20=$ serious; and 21-30=very serious. ${ }^{12}$ The study excluded patients with diagnosis of other subtypes of cancer, with relapsed cutaneous SCCs, in use of nonsteroidal anti-inflammatory drugs, in use of systemic corticosteroids, in use of tumor necrosis factor inhibitors (anti-TNF),

\section{CHART 1: Dimensions and domains assessed by the DLQI, validated in Portuguese ${ }^{12}$}

\section{Questions}

1. Over the last week, how itchy, sore, painful, or stinging has your skin been?

2. Over the last week, how embarrassed or self-conscious have you been because of your skin?

3. Over the last week, how much has your skin interfered with you going shopping or looking after your home or garden?

4. Over the last week, how much has your skin influenced the clothes you wear?

5. Over the last week, how much has your skin affected any social or leisure activities?

6. Over the last week, how much has your skin made it difficult for you to do any sport?

7. Over the last week, has your skin prevented you from working or studying? "No", over the last week how much has your skin been a problem at work or studying?

8. Over the last week, how much has your skin created problems with your partner or any of your close friends or relatives?

9. Over the last week, how much has your skin caused any sexual difficulties?

10. Over the last week, how much of a problem has the treatment for your skin been, for example, by making your home messy, or by taking up time?

Domains

Possible answers

Symptoms and feelings 3 - Very much

2 - A lot

1 - A little

0 - Not at all

Daily activities

3 - Very much

2 - A lot

1 - A little

0 - Not at all

Leisure

3 - Very much

2 - A lot

1 - A little

0 - Not at all

Work and school

3 - Very much

2 - A lot

1 - A little

0 - Not at all

Personal relations

3 - Very much

2 - A lot

1 - A little

0 - Not at all

Treatment

2 - A lot

1 - A little

0 - Not at all

DLQI: Dermatology Life Quality Index. Results with Likert score: 0-1: no effect; 2-5: small effect; 6-10: moderate effect; 11-20: serious effect and 21-30: very serious effect. Source: Finlay et al., 1994. ${ }^{12}$ 
with active inflammatory diseases, under 18 years of age, illiterate, and immunosuppressed individuals (such as those with primary immunodeficiency syndrome and/or renal transplant patients).

The surgical procedure was performed as proposed by Schultz, which consists of marking the tumor, where tumors less than $2 \mathrm{~cm}$ result in a margin of $10 \mathrm{~mm}$ and those larger than $2 \mathrm{~cm}$ in a margin of $15 \mathrm{~mm}$ (Figure 1)..$^{14,15}$

Statistical analysis described the continuous variables as means (standard deviation) or median (percentiles) after application of the Kolmogorov-Smirnov, Shapiro-Wilk, and Lilliefors tests of normality, and the categorical variables were described as absolute values and proportions. Measures of association were calculated by the chi-square test $(x 2)$ or Fisher's exact test, when appropriate, and odds ratios were also obtained. Statistical significance was determined with $95 \%$ confidence intervals and p-value $<0.05$. The analyses used the Statistical Package for the Social Sciences $\AA^{\circledR}$, version 22.0 (IBM SPSS Statistics, Chicago, Illinois, USA).

The study project was approved by the university's Institutional Review Board under number CAE - 51985215.6.0000.0121.
Patients' confirmed their voluntary participation by signing a free and informed consent form.

\section{RESULTS}

Of the 54 patients listed for the study, eight were excluded from the analysis (four illiterate patients and four with diagnoses other than SCC - two basosquamous carcinomas and two basal cell carcinomas) (Figure 2).

Of the 46 patients that were assessed, mean age was $67.1 \pm 16.0$ years, with 31 men $(67.4 \%)$, most of whom with outdoor occupations, or a total of $41(89.1 \%)$. Of these workers, $26(56.6 \%$ of the total) were farmers, and $58.7 \%$ were Fitzpatrick phototype II. ${ }^{16}$ The socioeconomic characteristics showed a predominance of low schooling (36 patients or $78.3 \%$ had incomplete primary schooling) and low income (38 patients or $82.6 \%$ of the sample earning up to twice the minimum wage, or about $\mathrm{U} \$ 480 /$ month). There was a personal history of skin cancer in $50 \%$ of the patients (23/46), and 20/46 (43.4) had a positive family history. Half of the sample had a single lesion and the other had multiple lesions. When quality of life was
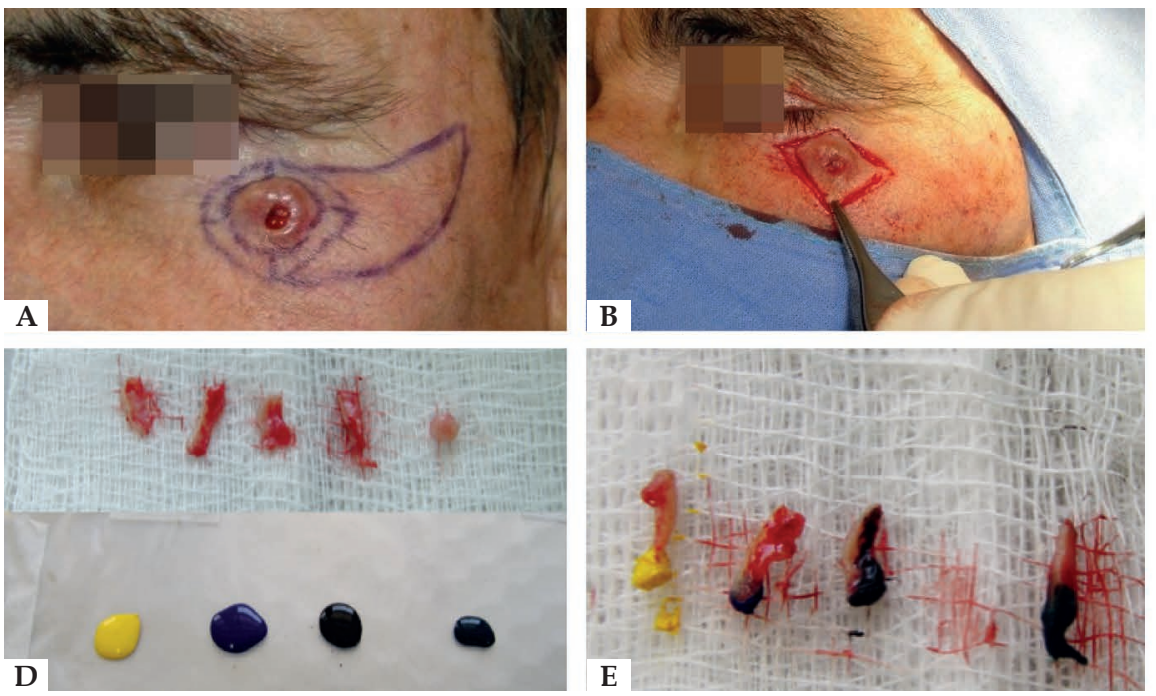
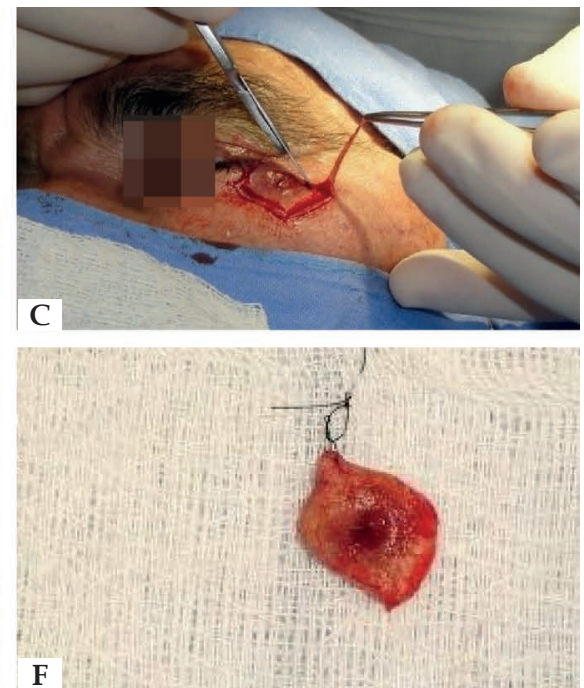

Figure 1: A - Marking margins; B - Excision of lesion with double-bladed scalpel; C - Removal of safety margin with double-bladed scalpel; D - Separation of margins for subsequent analysis and staining; E - Specimens marked with India ink; F - Marking with nylon suture at 12:00. Protocol for surgical procedure performed in patients with squamous cell skin cancer

Source: Girschik et al, 2008.17

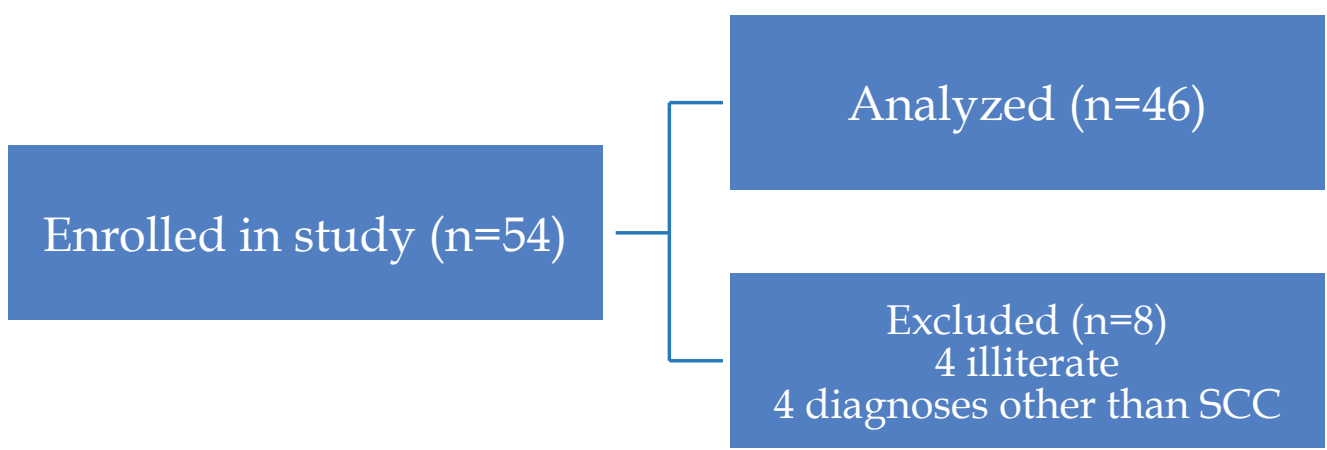

FIGURE 2: Flowchart of final sample: quality of life study in patients with SCC 
assessed on the basis of DLQI scores, the mean value was $4.02 \pm 0.63$; in the categorization, approximately one-fourth of patients $(23.98 \%)$ scored greater than five, indicating a moderate to severe negative effect on quality of life (Table 1).

The sample showed a high rate of solar exposure and low use of sunscreen. Mean exposure was $44.7 \pm 18.3$ years, and $82.6 \%$ were exposed to sun from 10:00 AM and 4:00 PM. Only 26 (56.5\%) individuals had ever used sunscreen (Table 2). Approximately half were smokers (54.3\%) and reported alcohol consumption (43.5\%). As for hats and protective clothing, 71.7\% reported regular use.

The lesions predominated on photoexposed areas, with head and neck as the most common (52.2\%), followed by upper limbs with $26.1 \%$. Three cases $(6.5 \%)$ had positive deep margins. Concerning analysis of the peripheral margins, no involvement was found with conventional anatomical pathological analysis, and one case $(2.2 \%)$ was observed when we used the double-bladed scalpel technique. We thus had one false-negative result (Table 3).

Table 4 shows the influence of lesions assessed by the DLQI score. Table 5 is the absolute distribution of the score on the answers obtained with the same quality of life questionnaire. Table 6 presents absolute numbers divided across the domains.

Graph 1 describes the percentage of the tumor's negative influence on individuals' quality of life in each of the categories, with the highest proportion found in activities of daily living $(33 \%)$,

\begin{tabular}{|c|c|}
\hline Variables & Values \\
\hline Age (years) $)^{£}$ & $67.1 \pm 16.0$ \\
\hline Male gender & $31(67.4 \%)$ \\
\hline \multicolumn{2}{|l|}{ Profession } \\
\hline Outdoor work & $41(89.1 \%)$ \\
\hline Indoor work & $5(10.9 \%)$ \\
\hline \multicolumn{2}{|l|}{ Skin phototype (Fitzpatrick) } \\
\hline II & $27(58.7 \%)$ \\
\hline III & $16(34.8 \%)$ \\
\hline IV & $3(6.5 \%)$ \\
\hline \multicolumn{2}{|l|}{ Schooling } \\
\hline Incomplete primary & $36(78.3 \%)$ \\
\hline Complete primary or more & $10(21.7 \%)$ \\
\hline \multicolumn{2}{|l|}{ Family income } \\
\hline Up to two times the minimum wage & $38(82.6 \%)$ \\
\hline$>2$ and $<6$ times the minimum wage & $8(16.4 \%)$ \\
\hline Personal history of skin cancer & $23(50.0 \%)$ \\
\hline Family history of skin cancer & $20(43.4 \%)$ \\
\hline \multicolumn{2}{|l|}{ Malignant lesions } \\
\hline Single & $23(50 \%)$ \\
\hline Multiple & $23(50 \%)$ \\
\hline
\end{tabular}

$£$ Mean \pm standard deviation; other values presented in absolute numbers (percentage); Fitzpatrick phototype ${ }^{16}$; DLQI - Dermatology Life Quality Index ${ }^{12}$ Source: Finlay et al., $1994^{12}$ and Gogia et al., 2013. ${ }^{16}$
TABLE 2: Comorbidities and life habits in patients with cutaneous squamous cell carcinoma $(n=46)$

Systemic arterial hypertension

$21(45.7 \%)$

Diabetes mellitus

$5(10.9 \%)$

Rheumatoid arthritis

Psoriasis/vitiligo

Smoking

Pack years* 25(20-40)

Alcohol abuse

Solar exposure (years)

$44.7 \pm 18.3$

Exposure between 10:00 AM and 4:00 PM

Chemical photoprotection (use of sunscreen)

Mechanical photoprotection

(use of hat or long clothing)

$33(71.7 \%)$

Data shown in absolute numbers (percentage)*Median (P25-P75); \# mean ( \pm standard deviation)

TABLE 3: Clinical/surgical and anatomical/pathological characteristics of cutaneous squamous cell carcinoma $(n=46)$

\section{Location}

Head and neck

$24(52.2 \%)$

Upper limbs

Trunk

$3(6.5 \%)$

Histological subtypes

In situ

Invasive

$19(41.3 \%)$

Differentiation by anatomical pathology

Poorly differentiated

Moderately differentiated

Well-differentiated

$8(17.4 \%)$

Layers invaded by lesion -

Assessed by anatomical pathology

Hypodermis

Papillary dermis

Reticular dermis

Positive deep margins

Positive peripheral margins

\section{Surgery performed}

Primary suture

Graft

Flap

Second intention

Duration of procedure (minutes) *

Data presented in absolute numbers (percentage);

*Median (minimum-maximum)

Data shown in absolute numbers (percentage)*Median (P25-P75); \# mean ( \pm standard deviation) 


\begin{tabular}{lc}
$\begin{array}{l}\text { TABLE 4: Patients' characteristics in relation to quality of life } \\
\text { measured by DLQI }\end{array}$ \\
Influence on quality of life (DLQI) \\
Not relevant (scores 0-1) & $15(32.0 \%)$ \\
Mild (2-5) & $20(43.5 \%)$ \\
Moderate (6-10) & $6(13.0 \%)$ \\
Severe (11-20) & $5(10.9 \%)$ \\
Very severe (21-30) & $0(0.0 \%)$ \\
Categorized DLQI & \\
1 -5 & $35(76.1 \%)$ \\
$>5$ & $11(23.9 \%)$ \\
Mean DLQI score & $4.02 \pm 0.63$ \\
\hline
\end{tabular}

${ }^{E}$ Mean \pm standard deviation; other values present in absolute numbers (percentage); DLQI - Dermatology Life Quality Index ${ }^{12}$

Source: Finlay et al, $1994 .{ }^{12}$ treatment-related effects (30\%), and symptoms and feelings (29\%). Table 7 categorizes the sample in two groups to diagnose protective and risk factors related to DLQI. The first group included individuals that scored less than five points (little or no influence on quality of life) and the second included values greater than five points (moderate, severe, and very severe). The odds ratio was 0.88 (CI: 0.22-3.43) when related to tumor location $(\mathrm{p}=0.03)$ (Table 7).

Individuals that presented severe influence on quality of life $(n=5)$, as expressed by a very high DLQI (11-20), are shown in Graph 2, with their individual scores subdivided by domains. All of them were men who presented lesions on the face or neck and were 50 to 60 years of age.

\section{DISCUSSION}

Squamous cell carcinoma accounts for only $20 \%$ of non-melanoma skin tumors but is responsible for the majority of the fatal cases. ${ }^{17}$ This neoplasm generally occurs in older men after chronic exposure to solar radiation, which may be due to the higher male

\section{TABLE 5: Dermatology Life Quality Index (DLQI): distribution of scores in patients with SCC}

\begin{tabular}{|c|c|c|c|c|c|c|c|}
\hline \multicolumn{8}{|c|}{ Score } \\
\hline Number & Question & 0 & 1 & 2 & 3 & Not relevant & Not completed \\
\hline 1 & Itching stinging/pain & 10 & 23 & 9 & 4 & - & 0 \\
\hline 2 & Embarrassment/self-consciousness & 25 & 14 & 6 & 1 & - & 0 \\
\hline 3 & Effect on household work & 15 & 17 & 11 & 3 & 0 & 0 \\
\hline 4 & Effect on clothing & 15 & 20 & 7 & 4 & 0 & 0 \\
\hline 5 & Effect on planning leisure time & 16 & 17 & 8 & 3 & 2 & 0 \\
\hline 6 & Effect on sports & 29 & 15 & 1 & 1 & 0 & 0 \\
\hline \multirow[t]{2}{*}{$7^{*}$} & Effect on work & - & 18 & 5 & - & 23 & 0 \\
\hline & If "no" to question 7 ( $n=18)$ & 12 & 6 & 0 & - & - & 0 \\
\hline 8 & Problems in relations with others & 17 & 20 & 7 & 2 & 0 & 0 \\
\hline 9 & Effect on love life & 23 & 19 & 3 & 1 & 0 & 0 \\
\hline 10 & $\begin{array}{l}\text { Problems resulting from treatments for skin } \\
\text { conditions }\end{array}$ & 17 & 18 & 9 & 1 & 1 & 0 \\
\hline
\end{tabular}

Source: Finlay et al, $1994 .^{12}$

TABLE 6: Distribution of quality of life scores in different domains in patients with squamous cell carcinoma

Quality of life n (\%)

\begin{tabular}{|c|c|c|c|c|c|c|}
\hline DLQI & Symptoms and feelings & Daily activities & Leisure & Work and school & Interpersonal relations & Treatment \\
\hline 0 & $9(19.6 \%)$ & $13(28.3 \%)$ & $14(30.4 \%)$ & $36(78.3 \%)$ & $17(37.0 \%)$ & $17(37.0 \%)$ \\
\hline 1 & $12(26.1 \%)$ & $5(10.9 \%)$ & $9(19.6 \%)$ & $5(10.9 \%)$ & $4(8.7 \%)$ & $18(39.1 \%)$ \\
\hline 2 & $13(28.3 \%)$ & $13(28.3 \%)$ & $13(28.3 \%)$ & $0(0.0 \%)$ & $18(39.1 \%)$ & $9(19.6 \%)$ \\
\hline 3 & $8(17.4 \%)$ & $5(10.9 \%)$ & $6(13.0 \%)$ & $5(10.9 \%)$ & $3(6.5 \%)$ & $2(4.4 \%)$ \\
\hline 4 & $2(4.3 \%)$ & $5(10.9 \%)$ & $3(6.3 \%)$ & - & $2(4.3 \%)$ & - \\
\hline 5 & $1(2.2 \%)$ & $4(8.7 \%)$ & $1(2.2 \%)$ & - & $1(2.2 \%)$ & - \\
\hline 6 & $1(2.2 \%)$ & $1(2.2 \%)$ & $0(0.0 \%)$ & - & $1(2.2 \%)$ & - \\
\hline Total & $46(100.0 \%)$ & $46(100.0 \%)$ & $46(100.0 \%)$ & $46(100.0 \%)$ & $46(100.0 \%)$ & $46(100.0 \%)$ \\
\hline
\end{tabular}

Source: Finlay et al, 1994. ${ }^{12}$ 


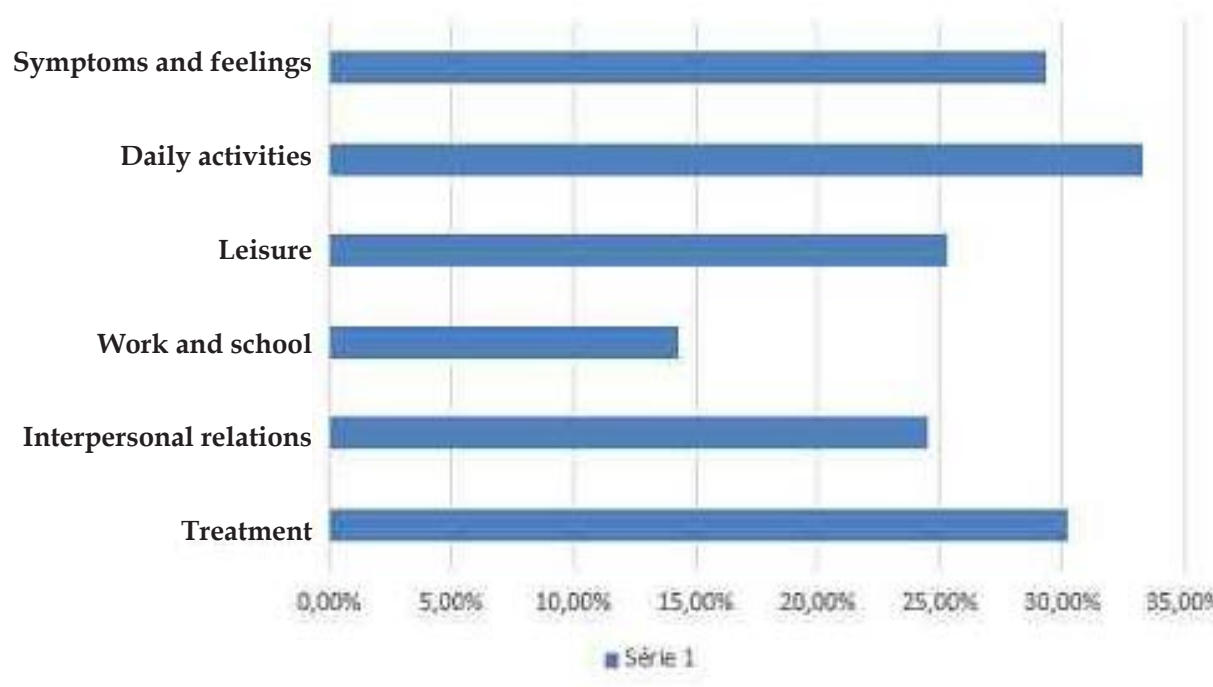

Graph 1: Percentage distribution of influence of quality of life scores in patients with squamous cell carcinoma $(n=46)$ participation in activities with cumulative exposure to UV rays. Approximately $97 \%$ of cases are associated with malignant progression of an actinic keratosis. ${ }^{3,8,9}$ However, it has increasingly affected the younger population, which may be explained by early detection, increasing use of tanning salons, ozone layer depletion, and increase in high-risk groups (organ transplant recipients and patients with bullous epidermolysis). ${ }^{18,19}$ The majority of our patients were males (67.4\%) and worked outdoors (89.1\%). ${ }^{6}$

Most of the patients with SCC had light skin (Fitzpatrick type II), low schooling (69.6\% had not finished primary school), and smoked (53.4\%; industrial cigarettes). ${ }^{20}$ These data corroborate other reports in the literature and were expected, since $85-90 \%$ of the population in Santa Catarina State are Caucasians (light-skinned), besides the fact that smoking increases the risk of this tumor 25-fold. ${ }^{20}$ Another important finding was that $43.4 \%$ of the individuals had a positive family history of skin cancer, since the risk of genetically transmitted predisposition is $50 \%$ per gestation, independently of gender, as previously demonstrated. ${ }^{21}$

Exposure to natural or artificial UV radiation is the risk factor most closely related to the development of SCC, so solar exposure should be avoided between 10:00 AM and 4:00 PM, when UV rays are the strongest (although many individuals that work during this period are unable to avoid it). In our sample, $82.6 \%$ of the patients reported solar exposure during this six-hour period, which can explain the tumor's predominance on surfaces unprotected from sunlight (78.3\%), such as the head, neck, and backs of the hands, corroborating data from the literature. ${ }^{22}$

Therefore, chemical and physical protection from sunlight play a crucial role in the prevention of this cancer. Sunscreen protects the skin by absorption or reflection of the UVA and UVB rays, but the difficulty in its use and constant reapplication are factors that decrease its acceptance. The most widely available sunscreen products on the market have to be reapplied every two hours. ${ }^{23}$ Only $26(56.5 \%)$ of the participants in this study had ever used sunscreen, which may be due to the high cost of the product and the educational issue. ${ }^{23}$ Physical protective methods such as hats, long clothing, and/or dark glasses were used by $71.7 \%$ of the participants.

Non-melanoma skin tumors are treated as chronic conditions without significant morbidity, but the sequelae from the disease and/or treatment can jeopardize the individual's psychosocial interaction, negatively influencing OoL. ${ }^{6,24}$ There are generic questionnaires (SF-36 and WHOQoL) and specific dermatological questionnaires (DLQI and SCI-Skin Cancer Index), which use QoL scores and associated factors, but thus far there is no gold standard instrument. ${ }^{12,25}$ The DLQI, used in this study, readily assesses chronic conditions and is validated in the Portuguese language, although it does not capture the patient's concern with recurrence or emergence of new lesions. The mean score in our sample was 4.02, higher than in other studies, such as Blackford (DLQI: 0.5) and Rhee (DLQI: $1.8)$, but these authors also included patients with premalignant lesions and BCC along with SCC. $6,26,27$

When we categorized the DLQI scores, we found that $23.9 \%$ of the tumors had a moderate to severe impact on the individuals' quality of life, while Steinbauer et al. reported $31 \% .^{28}$ In Nunes et al., who assessed only BCC, the proportion was $10.3 \%$, possibly because this tumor is less agressive. ${ }^{29}$ We also observed that treatment of tumor (33\%) and changes in activities of daily living (30) caused by the skin tumor had a negative influence on QoL. Steinbauer ${ }^{28}$ and Blackford ${ }^{26}$ found impairment in terms of symptoms and feelings, leisure-time activities, and activities of daily living.

The literature shows that skin tumors with ulceration, bleeding, signs of growth, or diameter greater than $2 \mathrm{~cm}$ negatively affect DLQI scores..$^{30}$ According to Mallon et al., women with lesions on the face and that undergo disfiguring treatment run greater risk of psychosocial dysfunction. Meanwhile, Shah \& Coates applied the DLQI and the Hospital Anxiety and Depression Scale (HADS) and found that patients with ulcerated lesions scored worse on quality of life. ${ }^{31-34}$ Therefore, the tumor's appearance and visibility can af- 
TABLE 7: Sociodemographic and clinical characteristics and use of protection from solar exposure according to Dermatology Life Quality Index (DLQI)

\begin{tabular}{|c|c|c|c|c|}
\hline \multicolumn{5}{|c|}{ DLQI scores } \\
\hline Characteristics & Not relevant or mild & $\begin{array}{c}\text { Moderate, severe, or } \\
\text { very severe }\end{array}$ & $\begin{array}{c}\text { odds ratio } \\
\text { (95\% confidence interval) }\end{array}$ & $p$-value ${ }^{\mu}$ \\
\hline \multicolumn{5}{|l|}{ Age (years) } \\
\hline$\leq 68$ & $16(72.7 \%)$ & $6(27.3 \%)$ & 0.70 (IC 0.18-2.73) & 0.26 \\
\hline$>68$ & $19(79.2 \%)$ & $5(20.8 \%)$ & & \\
\hline \multicolumn{5}{|l|}{ Gender } \\
\hline Male & $22(71.0 \%)$ & $9(29.0 \%)$ & 2.65 (IC 0.49-14.24) & 1.47 \\
\hline Female & $13(86.7 \%)$ & $2(13.3 \%)$ & & \\
\hline \multicolumn{5}{|l|}{ Work activities } \\
\hline Outdoor & $24(77.4 \%)$ & $7(22.6 \%)$ & 0.80 (IC 0.19-3.32) & 0.09 \\
\hline Indoor & $11(73.3 \%)$ & $4(26.7 \%)$ & & \\
\hline \multicolumn{5}{|l|}{ Fitzpatrick } \\
\hline II & $19(70.4 \%)$ & $8(29.6 \%)$ & 0.44 (IC 0.10-1.96) & 1.21 \\
\hline III-IV & $16(84.2 \%)$ & $3(15.8 \%)$ & & \\
\hline \multicolumn{5}{|l|}{ Monthly income } \\
\hline$\leq 2$ minimum wages & $28(73.7 \%)$ & $10(26.3 \%)$ & $0.40(0.04-3.66)$ & 0.65 \\
\hline 2-6 minimum wages & $7(87.5 \%)$ & $1(12.5 \%)$ & & \\
\hline \multicolumn{5}{|l|}{ Schooling } \\
\hline Incomplete primary & $26(72.2 \%)$ & $10(27.8 \%)$ & 0.28 (IC 0.03-2.58) & 1.56 \\
\hline$\geq$ complete primary & $9(90.0 \%)$ & $1(10.0 \%)$ & & \\
\hline \multicolumn{5}{|l|}{ Number of lesions } \\
\hline Single & $18(78.3 \%)$ & $5(21.7 \%)$ & 1.27 (IC 0.32-4.94) & 0.11 \\
\hline Multiple & $17(73.9 \%)$ & $6(26.1 \%)$ & & \\
\hline \multicolumn{5}{|l|}{ Smoking } \\
\hline Yes & $18(85.7 \%)$ & $3(14.3 \%)$ & 2.82 (IC 0.64-12.44) & 1.96 \\
\hline No & $17(68.0 \%)$ & $8(32.0 \%)$ & & \\
\hline \multicolumn{5}{|c|}{ Solar exposure 10AM-4PM } \\
\hline Yes & $7(87.5 \%)$ & $1(12.5 \%)$ & 2.50 (IC 0.27-22.93) & 0.65 \\
\hline No & $28(73.7 \%)$ & $10(26.3 \%)$ & & \\
\hline \multicolumn{5}{|l|}{ Sunscreen } \\
\hline Yes & $17(89.5 \%)$ & $2(10.5 \%)$ & 4.25 (IC 0.80-22.5) & 3.44 \\
\hline No & $18(66.7 \%)$ & $9(33.3 \%)$ & & \\
\hline \multicolumn{5}{|c|}{ Physical photoprotection } \\
\hline Yes & $10(76.9 \%)$ & $3(23.1 \%)$ & 1.06 (IC 0.23-4.85) & 0.007 \\
\hline No & $25(75.8 \%)$ & $8(24.2 \%)$ & & \\
\hline \multicolumn{5}{|l|}{ Tumor site } \\
\hline Head $\backslash$ neck & $18(75.0 \%)$ & $6(25.0 \%)$ & 0.88 (IC 0.22-3.43) & 0.03 \\
\hline Trunk \limbs & $17(73.3 \%)$ & $5(22.7 \%)$ & & \\
\hline
\end{tabular}

$"$ " - Use of chi-square test

fect the patient's wellbeing, but use of sunscreen can have a positive influence. ${ }^{22,35}$ We did not find any unique variable associated with altered quality of life.

Cancers located on visible areas, especially the face, do not show a significant improvement in QoL after treatment, except for tumors of the lip, which may be related to the functional aesthetic aspect. ${ }^{35}$ In the assessment of 183 patients with facial lesions (before and following treatment for four months), the DLQI and SCI showed that factors associated with better post-treatment QoL were female gender, age $<50$ years, primary lesions, and being employed. ${ }^{35}$ Importantly, preoccupations with facial scars and aesthetics are increasingly common in contemporary society.

Chen et $_{\text {al. }}{ }^{36}$, assessed patients in the pre and post-operative periods using Skindex-16 and found that individuals with tumors $<1 \mathrm{~cm}$ and in non-photoexposed areas presented better QoL before treatment. One study that included non-melanoma skin tumors 


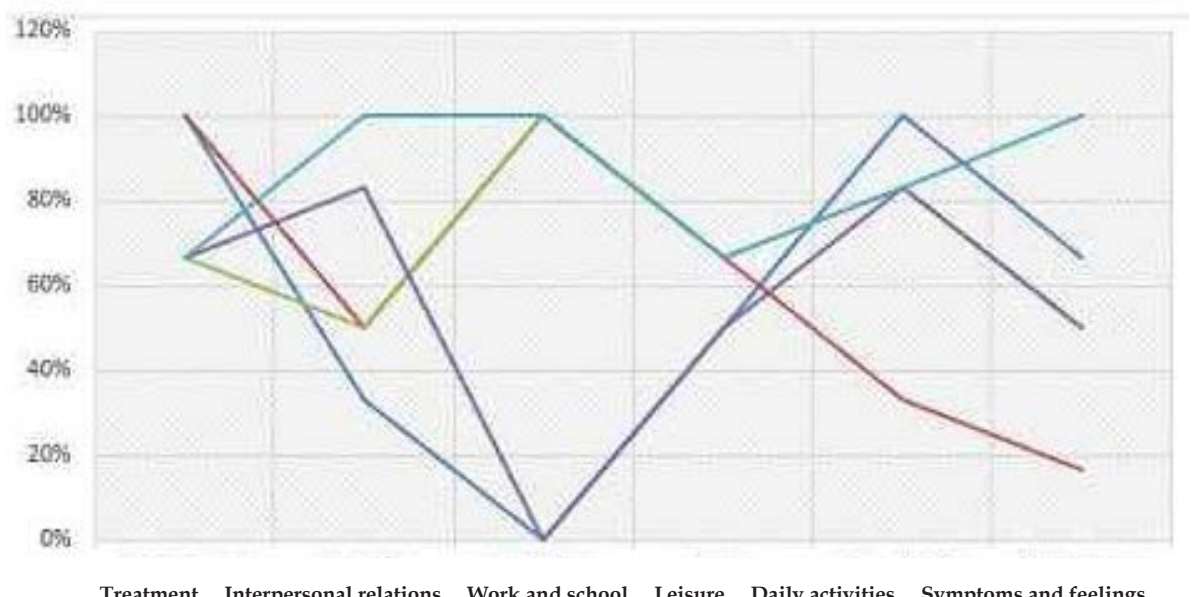

Treatment Interpersonal relations Work and school Leisure Daily activities Symptoms and feelings
GRAPH 2: Quality of life index in patients with very high score (11-20) in different domains and location of SCC

P 17: 59 years (A), malar region, DLQI: 20; P 20: 54 A, pre-auricular region, DLQI:11; P 48: $57 \mathrm{~A}$, auricular region, DLQI: 13; P 12: $53 \mathrm{~A}$, pre-auricular region, DLQI: 11 and P 29: $53 \mathrm{~A}$, malar region, DLQI: 12

Legend: $\mathrm{P}=$ patient and respective identification number, age, location of SCC, quality of life index, very high score (11 to 20) found that low income also predicted significant improvement in QoL after treatment, while another study using a generic scale (SF-36) found a minimal impact in patients with initial diagnosis of non-melanoma skin cancer. ${ }^{35}$ It is possible that generic questionnaires are unable to assess the real influence of skin diseases on QoL.

There is no evidence to date that the tumor's subtype or demographic characteristics independently predict post-operative QoL, which is not true in the pre-operative assessment. When we used DLQI prior to surgical resection and identified patients with moderate to severe impact on QoL, they were all males, had facial lesions, and were in their fifties (Graph 2). This corroborates the discussion above and findings from the literature in various studies that used this same questionnaire.

There is no gold standard for assessing QoL in dermatological patients, but the DLQI is a good instrument for assessing quality of life in individuals with skin cancer, although it was not created specifically for this purpose. ${ }^{37}$ There are other limitations, for ex- ample that the sample did not include immunosuppressed patients and/or those with relapsed lesions, besides the cross-sectional design. A longitudinal design and pre- and pos-operative follow-up could establish a relationship between the variables at these different time points, but this was not the purpose of the study.

\section{CONCLUSION}

In this sample of patients with clinical and histopathological diagnosis of SCC, we showed a predominance of elderly males with low schooling and low socioeconomic status, working in outdoor activities, with Fitzpatrick phototype II, and with tumors located on the head and neck. One-fourth of the patients presented a moderate to severe negative effect on quality of life prior to the surgical procedure, in addition to a negative influence from the disease on daily activities (33\% of cases), treatment effects (30\%), and symptoms and feelings $(29 \%)$.

\section{REFERENCES}

1. Brasil. Ministério da Saúde. Instituto Nacional de Câncer José Alencar Gomes da Silva. Coordenação de Prevenção e Vigilância. Estimativa 2018: incidência de câncer no Brasil. Rio de Janeiro: INCA, 2017.

2. Nasser N, Nasser Filho N, Lehmkuhl RL. Squamous cell cancer--31-year epidemiological study in a city of south Brazil. An Bras Dermatol. 2015;90:21-6.

3. Owczarek W, Majewski S, Schwartz RA.. Risk factors for squamous cell carcinoma of the skin with two illustrative cases and literature review. Acta Dermatovenerol Croat. 2011;19:21-7.

4. Brash DE, Ziegler A, Jonason AS, Simon JA, Kunala S, Leffell DJ. Sunlight and sunburn in human skin cancer: p53, apoptosis, and tumor promotion. J Investig Dermatol Symp Proc. 1996;1:136-42.

5. Mendenhall WM, Ferlito A, Takes RP, Bradford CR, Corry J, Fagan JJ, et al. Cutaneous head and neck basal and squamous cell carcinomas with perineural invasion. Oral Oncol. 2012;48:918-22.
6. Katz MR, Irish JC, Devins GM, Rodin GM, Gullane PJ. Psychosocial adjustment in head and neck cancer: the impact of disfigurement, gender and social support. Head Neck. 2003;25:103-12.

7. Braathen LR, Szeimies RM, Basset-Seguin N, Bissonnette R, Foley P, Pariser D, et al. Guidelines on the use of photodynamic therapy for nonmelanoma skin cancer: an international consensus. International Society for Photodynamic Therapy in Dermatology, 2005. J Am Acad Dermatol. 2007;56:125-43.

8. Clayman GL, Lee JJ, Holsinger FC, Zhou X, Duvic M, El-Naggar AK, et al. Mortality risk from squamous cell skin cancer. J Clin Oncol. 2005;23:759-65.

9. Lee EH, Klassen AF, Nehal KS, Cano SJ, Waters J, Pusic AL. A systematic review of patient-reported outcome instruments of nonmelanoma skin cancer in the dermatologic population. J Am Acad Dermatol. 2013;69:e59-67.

10. Weinstock MA. The epidemic of squamous cell carcinoma. JAMA. 1989;262:213840. 
11. Rowe DE, Carroll RJ, Day CL. Prognostic factors for local recurrence, metastasis, and survival rates in squamous cell carcinoma of the skin, ear, and lip. Implications for treatment modality selection. J Am Acad Dermatol. 1992 Jun;26(6):976-90.

12. Finlay AY, Khan GK. Dermatology Life Quality Index (DLQI)--a simple practical measure for routine clinical use. Clin Exp Dermatol. 1994;19:210-6.

13. Martins GA, Arruda L, Mugnaini ASB. Validation of life quality questionnaires for psoriasis patients. An Bras Dermatol. 2004;79:521-35

14. Schultz BC, Roenigk HH Jr. The double scalpel and double punch excision of skin tumors. J Am Acad Dermatol. 1982;7:495-9.

15. Miller SJ, Alam M, Andersen J, Berg D, Bichakjian CK, Bowen G, et al. Basal cell and squamous cell skin cancers. J Natl Compr Canc Netw. 2010;8:836-64.

16. Gogia R, Binstock M, Hirose R, Boscardin WJ, Chren M-M, Arron ST. Fitzpatrick skin phototype is an independent predictor of squamous cell carcinoma risk after solid organ transplantation. J Am Acad Dermatol. 2013;68:585-91.

17. Girschik J, Fritschi L, Threlfall T, Slevin T. Deaths from non-melanoma skin cancer in Western Australia. Cancer Causes Control. 2008;19:879-85

18. Christenson LJ, Borrowman TA, Vachon CM, Tollefson MM, Otley CC, Weaver AL, et al. Incidence of basal cell and squamous cell carcinomas in a population younger than 40 years.JAMA. 2005;294:681-90.

19. Gray DT, Suman VJ, Su WP, Clay RP, Harmsen WS, Roenigk RK. Trends in the population-based incidence of squamous cell carcinoma of the skin first diagnosed between 1984 and 1992. Arch Dermatol. 1997;133:735-40.

20. Inca.gov.br [Internet] Brasil. Ministério da Saúde. Instituto Nacional de Câncer José Alencar Gomes da Silva. Coordenação de Prevenção e Vigilância. Estimativa 2014: Incidência de Câncer no Brasil. 2014;124. Available from: http://www.inca. gov.br/estimativa/2014/sintese-de-resultados-comentarios.asp

21. Dias R, Silva D, Aparecida M, Dias I. Incidence of basal cell and squamous cell carcinomas among users attended in a cancer hospital. REFACS (online) 2017;5:228-34

22. Al Robaee AA. Awareness to sun exposure and use of sunscreen by the general population. Bosn J Basic Med Sci. 2010;10:314-8.

23. Wesson KM, Silverberg NB. Sun protection education in the United States: what we know and what needs to be taught. Cutis. $2003 ; 71: 71-4,77$

24. Al-Ghazal SK, Sully L, Fallowfield L, Blamey RW. The psychological impact of immediate rather than delayed breast reconstruction. Eur J Surg Oncol. 2000;267-9. 25. Brazier JE, Harper R, Jones NM, O'Cathain A, Thomas KJ, Usherwood T, et al.
Validating the SF-36 health survey questionnaire: new outcome measure for primary care. BMJ. 1992;305:160-4

26. Blackford S, Roberts D, Salek MS, Finlay A. Basal cell carcinomas cause little handicap. Qual Life Res. 1996:5:191-4.

27. Rhee JS, Matthews BA, Neuburg M, Smith TL, Burzynski M, Nattinger AB.. Quality of Life and Sun-Protective Behavior in Patients With Skin Cancer. Arch Otolaryngol Head Neck Surg. 2004;130:141-6.

28. Steinbauer J, Koller M, Kohl E, Karrer S, Landthaler M, Szeimies RM.. Quality of life in health care of non-melanoma skin cancer - results of a pilot study. J Dtsch Dermatol Ges. 2011;9:129-35

29. Nunes DH. Carcinoma basocelular: estimativa da qualidade de vida, infiltrado inflamatório e avaliação das margens laterais após exérese por bisturi de lâmina dupla [tese]. Florianópolis (SC): Universidade Federal de Santa Catarina; 2013.

30. Rhee JS, Matthews BA, Neuburg M, Logan BR, Burzynski M, Nattinger AB The skin cancer index: clinical responsiveness and predictors of quality of life. Laryngoscope. 2007;117:399-405.

31. Morgan M, McCreedy R, Simpson J, Hay RJ. Dermatology quality of life scales--a measure of the impact of skin diseases. Br J Dermatol. 1997;136:202-6.

32. Mallon E, Newton JN, Klassen A, Stewart-Brown SL, Ryan TJ, Finlay AY. The quality of life in acne: a comparison with general medical conditions using generic questionnaires. Br J Dermatol. 1999;140:672-6.

33. Farasat S, Yu SS, Neel VA, Nehal KS, Lardaro T, Mihm MC, et al. A new American Joint Committee on Cancer staging system for cutaneous squamous cell carcinoma: creation and rationale for inclusion of tumor (T) characteristics. J Am Acad Dermatol. 2011;64:1051-9.

34. Wu Y, Fu C, Zhang W, Li C, Zhang J. The dermatology life quality index (DLQI) and the hospital anxiety and depression (HADS) in Chinese rosacea patients. Psycho Health Med. 2018;23:369-374

35. Rodriguez-Vigil T, Vázquez-López F, Perez-Oliva N. Recurrence rates of primary basal cell carcinoma in facial risk areas treated with curettage and electrodesiccation. J Am Acad Dermatol. 2007:56:91-5.

36. Chan A, Cameron MC, Garden B, Boers-Doets CB, Schindler K, Epstein JB, et al. A systematic review of patient-reported outcome instruments of dermatologic adverse events associated with targeted cancer therapies. Support Care Cancer. 2015 Aug;23(8):2231-44.

37. Dixon AJ, Dixon MP, Dixon JB. Prospective study of long-term patient perceptions of their skin cancer surgery. J Am Acad Dermatol. 2007;57:445-53.

AUTHORS'CONTRIBUTIONS

Daniel Ongaratto Barazzetti

(iD) ORCID

0000-0002-5922-3386

Statistical analysis; Approval of the final version of the manuscript; Study conception and planning; Elaboration and drafting of the manuscript; Obtaining, analyzing, and interpreting the data; Effective participation in research orientation; Intellectual participation in the propaedeutic and/or therapeutic conduct of the cases; Critical review of the literature; Critical review of the manuscript

Pedro Henrique Ongaratto Barazzetti $\quad$ (ID) ORCID 0000-0001-6255-5210

Statistical analysis; Elaboration and drafting of the manuscript; Conception and planning of the study

Bárbara Thomé Cavalheiro $\quad$ (iD) ORCID 0000-0003-4097-8153

Approval of the final version of the manuscript; Critical review of the literature; Elaboration and drafting of the manuscript; Critical review of the manuscript

Jorge Bins Ely

(iD) ORCID

0000-0002-8226-0062

Statistical analysis; Approval of the final version of the manuscript; Conception and planning of the study; Elaboration and drafting of the manuscript; Effective participation in research orientation; Intellectual participation in the propaedeutic and/or therapeutic conduct of the cases; Critical review of the literature; Critical review of the manuscript Daniel Holthausen Nunes $\quad$ (iD) ORCID 0000-0001-5863-555X

Statistical analysis; Approval of the final version of the manuscript; Conception and planning of the study; Elaboration and drafting of the manuscript; Obtaining, analyzing, and interpreting the data; Effective participation in research orientation; Intellectual participation in the propaedeutic and/or therapeutic conduct of the cases; Critical review of the literature; Critical review of the manuscript

Ana Maria Nunes de Faria Stamm $\quad$ (iD) ORCID $\quad 0000-0001-5186-1247$

Statistical analysis; Approval of the final version of the manuscript; Conception and planning of the study; Obtaining, analyzing, and interpreting the data; Effective participation in research orientation; Intellectual participation in the propaedeutic and/or therapeutic conduct of the cases; Critical review of the literature; Critical review of the manuscript

How to cite this article: Barazzetti DO, Barazzetti PHO, Cavalheiro BT, Ely JB, Nunes DH, Stamm AMNF. Quality of life and clinical and demographic characteristics of patients with cutaneous squamous cell carcinoma submitted to tumor resection by double-bladed scalpel. An Bras Dermatol. 2019;94(3):304-12. 